\title{
HYDROPHILIZATION OF POLYVINYLIDENE FLUORIDE (PVDF) NANOFIBERS BY PLASMA TREATMENT AND ITS EFFECT ON NANOPARTICLE DEPOSITION
}

\author{
1'Veronika KAŽıKOVÁ, '1 Július VIDA, ${ }^{2} P e t r$ RYŠÁNEK, ${ }^{2}$ Martin KORMUNDA, ${ }^{2}$ Pavla ČAPKOVÁ, \\ ${ }^{1}$ Tomáš HOMOLA
}

${ }^{1}$ MUNI - Masaryk University, Brno, Czech Republic, EU, 517378@mail.muni.cz

2J. E. Purkyne University, Ústí nad Labem, Czech Republic, EU

https://doi.org/10.37904/nanocon.2021.4325

\begin{abstract}
Polyvinylidene fluoride (PVDF) polymeric nanofibers deposited by roller electrospinning on polypropylene nonwoven fabric were treated with atmospheric pressure plasma to hydrophilize its surface. Diffuse coplanar surface barrier discharge (DCSBD) was employed to generate low-temperature atmospheric plasma in ambient air. Changes in wettability were determined by evaluating water contact angles before and after plasma treatment for various treatment times. The effect of aging of plasma-treated surfaces stored in laboratory conditions was studied in the course of storage time. The chemical composition of the surfaces was determined by X-ray photoelectron spectroscopy (XPS) which showed a decrease in carbon and an increase in oxygen atomic concentrations. Subsequently, significant differences in loading of iron oxide nanoparticles between treated and untreated PVDF samples were observed by scanning electron microscopy.
\end{abstract}

Keywords: DCSBD plasma source, PVDF, wettability, water contact angle, iron oxide nanoparticles

\section{INTRODUCTION}

Polyvinylidene fluoride (PVDF) nanofibers are a promising type of polymeric nanofibers thanks to their large surface area-to-volume ratio, flexibility, fine pore texture and more advantageous properties used in many nano- or biotechnological applications in medicine, cosmetics, electronics manufacturing, metallurgy or for designing nanocomposite membranes. Such membranes can utilize the adsorption of porous fibres and loaded nanoadsorbers for water filtration, which is one of the most significant concerns in many ever-growing industries, polluting Earth's water resources [1,2]. As nanoadsorbers, iron oxide nanoparticles, attracted interest, due to many desirable properties of reactivity, adsorption, catalytic properties or low cost [1]. Especially magnetite nanoparticles represent a promising method of adsorbing heavy metal pollutants from water, with an ability to easily manipulate them with a magnetic field [3].

In such processes, the wettability of used porous material is crucial and low wettability is a disadvantage of using PVDF in contrast to its superior chemical, thermal and mechanical properties. Thus, enhancing the wettability of PVDF is desired not only in water filtration, but for example also in the preparation of stimuliresponsive membranes $[4,1]$. Traditionally, chemical hydrophilization techniques such as coating with hydrophilic polymer solutions are widely applied [1]. Creating a PVDF mixed matrix by blending PVDF with the deformed rebar-like $\mathrm{Fe}_{3} \mathrm{O}_{4}$-palygorskite nanocomposites has also proved to lower the water contact angle by around $20^{\circ}$ [5]. In this work, we present an alternative low-cost method for hydrophilization, which is more environmentally friendly than often used chemical methods, by using low-temperature plasma surface treatment. Plasma treatment is a very effective method for changing surface properties and enhancing wettability [6]. Especially for treatments of polymers, plasma sources with low working temperatures are desirable. This condition is met with diffuse coplanar surface barrier discharge (DCSBD) with a working 
temperature of around $70^{\circ} \mathrm{C}$, the ability to use in ambient air, so no vacuum setup is needed and configuration ideal for the treatment of larger surfaces.

\section{EXPERIMENT}

PVDF polymeric nanofibers were deposited on polypropylene (PP) non-woven fabric by electrospinning. Samples were cut into approximately $1 \mathrm{~cm} \times 1 \mathrm{~cm}$ pieces, placed onto a glass substrate and its surface was treated with plasma. DCSBD, commercialized by MUNI spin-off Roplass s.r.o., Czech Republic was used as a source of low-temperature atmospheric pressure plasma. It is a type of dielectric barrier discharge consisting of parallel electrodes embedded in a ceramic plate. As working an ambient air was used. To ensure the samples are treated with a diffuse part of a plasma, samples were moved during treatment back and forth on the discharge plane. The samples were during treatment in direct contact with a discharge plate to ensure plasma was present in the space between the nanofibers inside the sample. The treatment time was varied between $2 \mathrm{~s}$ and $16 \mathrm{~s}$. Aging of the samples was determined after 7, 14 and 30 days of storage.

Wettability of untreated and treated samples was evaluated by dropping $1 \mu \mathrm{m}$ water droplet with a pipette on the surface and contact angle was analysed with See system (Advex Instruments, Czech Republic).

The chemical composition of the surface and bonding states were analysed from X-ray photoelectron spectroscopy (XPS) spectra, obtained by AXIS Supra spectrometer (Kratos Analytical Ltd., United Kingdom). Data were calibrated to $\mathrm{C}-\mathrm{H}$ peak at $285.0 \mathrm{eV}$ in $\mathrm{C} 1$ s narrow region. Background $\mathrm{U}$ Poly Tougaard was used, line shapes for fitting were mixed Gaussian-Lorentzian.

$\mathrm{Fe}_{2} \mathrm{O}_{3}$ magnetite nanoparticle powder (Sigma-Aldrich, $<100 \mathrm{~nm}$ ) was dispersed in dowanol PM (1:4) and milled in a glass vial with glass balls at $900 \mathrm{rpm}$ for 10 days. After milling, the suspension was mixed with polysiloxane binder and dissolved in ethanol in ratio 6:2. The concertation of polysiloxane in ethanol was $20 \%$ and the process is described in detail in [7]. Then the suspension was further diluted in dowanol PM in a 1:10 ratio and dropped with a $2 \mu \mathrm{m}$ volume pipette on the untreated and plasma treated PVDF. After drying, the samples with deposited nanoparticles were sputtered with $10 \mathrm{~nm}$ thick $\mathrm{Au}+\mathrm{Pd}$ film and imaged with MIRA3 scanning electron microscope (Tescan, Czech Republic) with Schottky field emission electron gun. Images were obtained by secondary electron detector, while the accelerating voltage was set to $8 \mathrm{kV}$ and working distance to $15 \mathrm{~mm}$.

\section{RESULTS AND DISCUSSION}

\subsection{Wettability}

Changes in water contact angle (WCA) were observed after plasma treatment in ambient air. The untreated PVDF surface showed WCA of $95^{\circ} \pm 6^{\circ}$ and ambient air plasma treatment for $2 \mathrm{~s}$ was enough to increase the wettability of PVDF to the extend it was not possible to measure the static WCA, as droplets were immediately absorbed by nanofibers PVDF surface. The aging behaviour of the PDFV after the plasma treatment for $8 \mathrm{~s}$ was evaluated after 7,14 and 30 days. The results showed that the ambient air plasma treated sample retained its increased wettability even after a month. The plasma treatment was repeated with setting the distance between PVDF sample and plasma plane to $0.3 \mathrm{~mm}$, as usually used to treat surfaces with DCSBD to ensure the best interaction with plasma. However, this led to no change in wettability whatsoever, suggesting that PVDF nanofibers must be in direct contact with the DCSDB ceramics in order to plasma sufficiently enter the space between nanofibers.

\subsection{Chemical analysis of PVDF after plasma treatment}

In Table 2 can be seen individual atomic concentration changes obtained from high resolution X-ray photoelectron spectroscopy (XPS) regions and the ratio of C:O concentrations. The ratio decrease can be 
clearly seen after plasma treatment. This suggests surface cleaning processes of plasma from carbon contaminations. Even 2 seconds of plasma treatment was enough to decrease the carbon concentration and increase the concentration of oxygen and fluorine. Longer plasma treatments do not change the chemical composition of the surface significantly. Traces of potassium, phosphorus and sodium were detected on the surface, decreasing slightly after plasma treatment. Moreover, some amount of nitrogen was incorporated into the surface during treatment.

Table 2 Atomic concentrations of untreated and ambient air plasma-treated PVDF polymer, obtained from high-resolution XPS regions

\begin{tabular}{|c|c|c|c|c|c|c|c|c|}
\hline $\begin{array}{l}\text { Treatment } \\
\text { time }\end{array}$ & C [\%] & F [\%] & $\mathrm{O}$ [\%] & $\mathrm{K}$ [\%] & P [\%] & $\mathrm{Na}$ [\%] & N [\%] & C:O ratio \\
\hline $0 \mathrm{~s}$ & $\begin{array}{r}56.3 \\
\pm 0.4 \\
\end{array}$ & $\begin{array}{r}23 \\
\pm 1 \\
\end{array}$ & $\begin{array}{r}12.3 \\
\pm 0.3 \\
\end{array}$ & $\begin{array}{c}2.7 \\
\pm 0.2 \\
\end{array}$ & $\begin{array}{c}3.5 \\
\pm 0.2 \\
\end{array}$ & $\begin{array}{c}1.7 \\
\pm 0.1 \\
\end{array}$ & $\begin{array}{c}0 \\
\pm 0 \\
\end{array}$ & $4.6 \pm 0.1$ \\
\hline $2 \mathrm{~s}$ & $\begin{array}{r}48.6 \\
\pm 0.4 \\
\end{array}$ & $\begin{array}{r}29.90 \\
\pm 0.01 \\
\end{array}$ & $\begin{array}{r}15.0 \\
\pm 0.3 \\
\end{array}$ & $\begin{array}{r}2.44 \\
\pm 0.01 \\
\end{array}$ & $\begin{array}{c}2.6 \\
\pm 0.2 \\
\end{array}$ & $\begin{array}{c}0.68 \\
\pm 0.01 \\
\end{array}$ & $\begin{array}{c}0.8 \\
\pm 0.1 \\
\end{array}$ & $\begin{array}{c}3.25 \pm \\
0.08 \\
\end{array}$ \\
\hline $4 \mathrm{~s}$ & $\begin{array}{l}49.0 \\
\pm 0.1\end{array}$ & $\begin{array}{r}30.26 \\
\pm 0.08 \\
\end{array}$ & $\begin{array}{r}14.7 \\
\pm 0.4\end{array}$ & $\begin{array}{c}2.13 \\
\pm 0.08 \\
\end{array}$ & $\begin{array}{c}2.28 \\
\pm 0.07\end{array}$ & $\begin{array}{c}0.58 \\
\pm 0.07\end{array}$ & $\begin{array}{c}1.0 \\
\pm 0.1\end{array}$ & $\begin{array}{c}3.32 \pm \\
0.08\end{array}$ \\
\hline $8 \mathrm{~s}$ & $\begin{array}{r}48.58 \\
\pm 0.06 \\
\end{array}$ & $\begin{array}{r}29.5 \\
\pm 0.7 \\
\end{array}$ & $\begin{array}{r}16.1 \\
\pm 0.5 \\
\end{array}$ & $\begin{array}{c}2.0 \\
\pm 0.2 \\
\end{array}$ & $\begin{array}{c}2.3 \\
\pm 0.2 \\
\end{array}$ & $\begin{array}{c}0.47 \\
\pm 0.02 \\
\end{array}$ & $\begin{array}{c}1.1 \\
\pm 0.3 \\
\end{array}$ & $3.0 \pm 0.1$ \\
\hline $16 s$ & $\begin{array}{l}50.93 \\
\pm 0.07\end{array}$ & $\begin{array}{l}29.7 \\
\pm 0.5\end{array}$ & $\begin{array}{l}14.1 \\
\pm 0.9\end{array}$ & $\begin{array}{c}1.5 \\
\pm 0.2\end{array}$ & $\begin{array}{c}2.1 \\
\pm 0.3\end{array}$ & $\begin{array}{c}0.36 \\
\pm 0.06\end{array}$ & $\begin{array}{c}1.3 \\
\pm 0.3\end{array}$ & $3.6 \pm 0.2$ \\
\hline
\end{tabular}

Figure 1 shows intensities of XPS $\mathrm{C}$ 1s and $\mathrm{O}$ 1s peaks individual components and their evolution with plasma treatment time. In Figure 2, shapes of $C$ 1s XPS spectra and deconvoluted components can be seen for reference and $2 \mathrm{~s}$ plasma treated sample in ambient air. $\mathrm{C}$ 1s spectrum was deconvoluted into five components: C-H/C-C (285.0 eV), C-OH/C-O-C (286.3 eV), C=O (288.0 eV), O-C=O $(289.0 \mathrm{eV})$ and C-F2 $(290.7 \mathrm{eV})$. Because $\mathrm{K} 2 \mathrm{p}$ region overlaps with the $\mathrm{C} 1 \mathrm{~s}$ region, the intensities of $\mathrm{K} 2 \mathrm{p}$ peaks was set to zero. After ambient air plasma the intensity of $\mathrm{C}-\mathrm{C} / \mathrm{C}-\mathrm{H}$ component decreased, indicating surface cleaning from hydrocarbon contamination. Moreover, a significant increase in $\mathrm{O}-\mathrm{C}=\mathrm{O}$ component is observed, caused by oxygen species in the plasma.

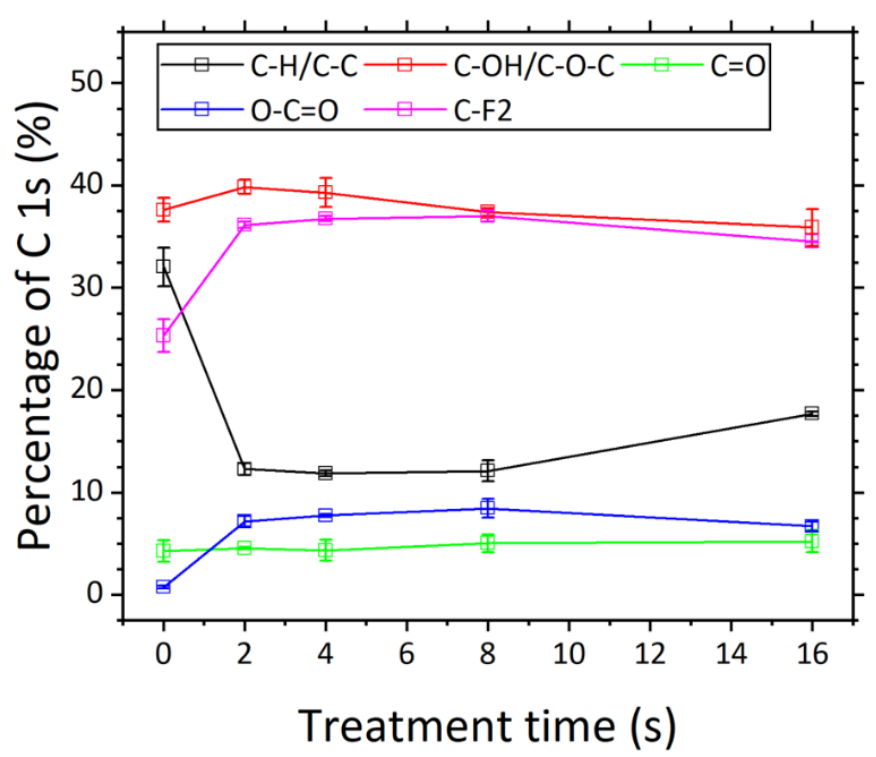

Figure 1 Changes in the intensities of individual components of the $C 1$ s peak in XPS spectrum 

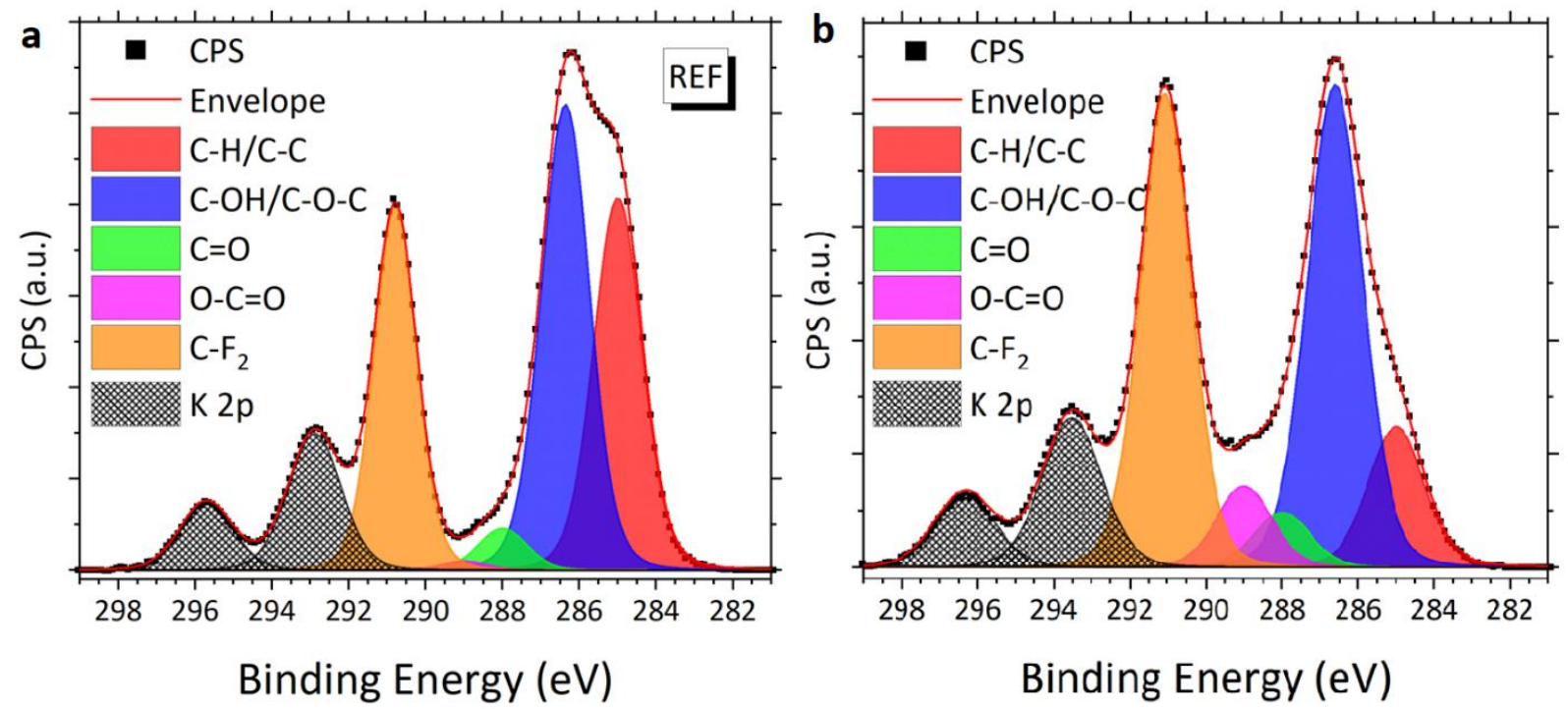

Figure 2 Changes in the shape and components of $C$ 1s narrow regions in XPS spectra due to ambient air plasma treatment for $2 \mathrm{~s}$ (b) compared with reference sample (a).

\subsection{Deposition of nanoparticles on plasma treated PVDF}

The untreated and plasma treated PVDF nanofibers with deposited magnetite particles, are shown in Figure 3. Due to the wettability results, only an ambient air plasma was utilized in this experiment and treatment time was set to 2 seconds, as longer treatment did not produce significantly better results. Images revealed that fibres on the sample without plasma treatment were wrapped in dried solution. However, on the sample with plasma treatment, solution wetted the fibres to the higher extend, getting deeper into the sample and leaving more nanoparticles on the surface of fibres.

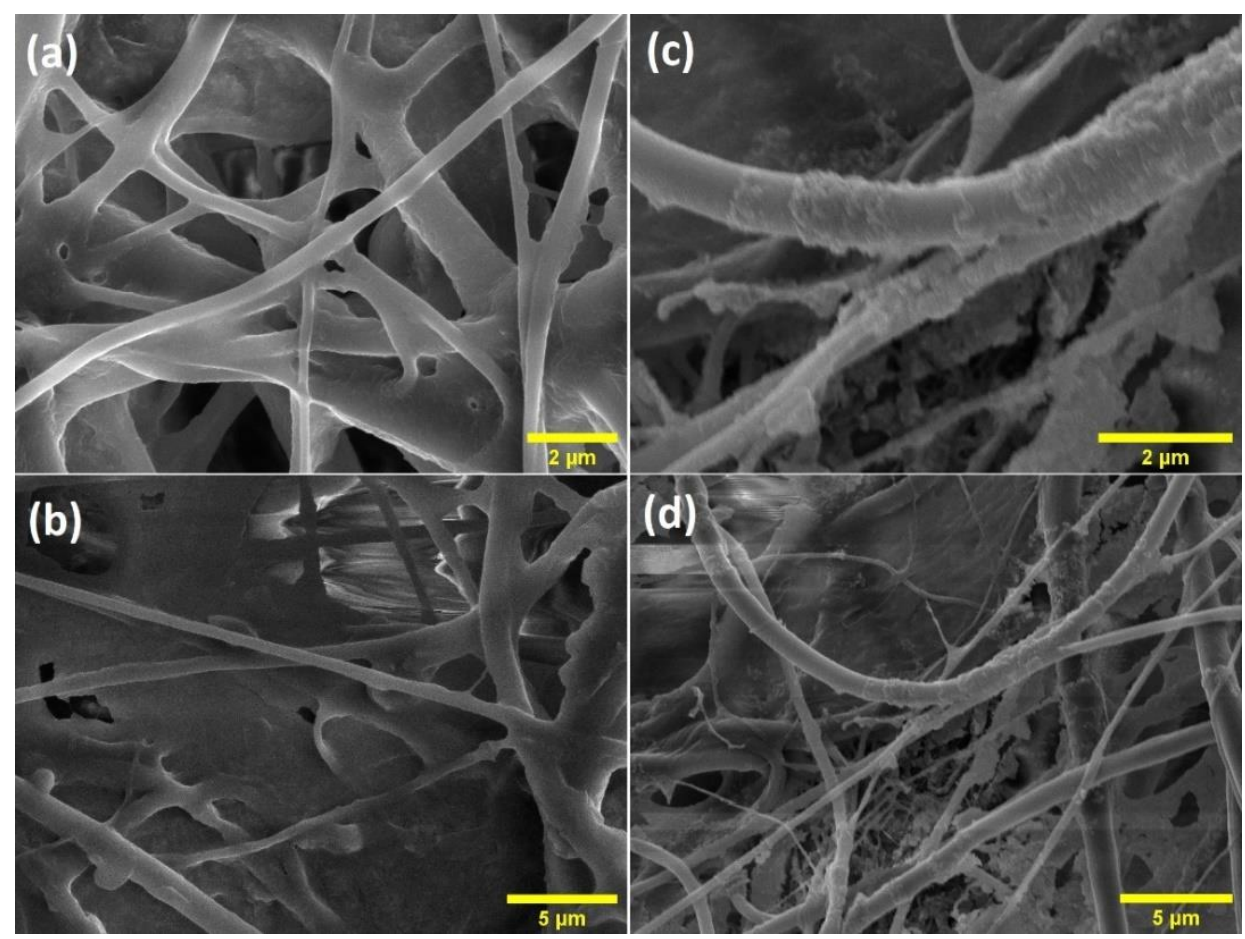

Figure 3: SEM images of nanoparticle solution deposited on untreated PVDF nanofibers (a, and $\mathbf{b}$,) and $2 \mathrm{~s}$ ambient air plasma treated PVDF nanofibers (c, and $\mathbf{d}$,). 


\section{CONCLUSION}

We achieved a change of the water contact angle of PVDF nanofibers increasing its wettability with a low temperature DCSBD plasma source in ambient air. Chemical composition analysis revealed a possible cleaning effect of plasma from hydrocarbon contamination and functionalization of its surface by polar oxygencontaining groups. The PVDF surface with enhanced wettability showed an increased ability to adsorb more magnetite nanoparticles on nanofibers surface.

\section{ACKNOWLEDGEMENTS}

This research was supported by GACR projects 19-14770Y and projects LM2018097, LM2018110 funded by the Ministry of Education, Youth and Sports of the Czech Republic.

\section{REFERENCES}

[1] ABDALI, N., MARJANI, A., HEIDARY, F., ADIMI, M. Fabrication of PVA coated PES/PVDF nanocomposite membranes embedded with in situ formed magnetite nanoparticles for removal of metal ions from aqueous solutions. New j. Chem. 2017, vol. 41, pp. 6405-6414.

[2] ASMATULU, R., MUPPALLA, H., VEISI, Z., KHAN, W.S., ASADUZZAMAN, A., NURAJE, N. Study of hydrophilic electrospun nanofiber membranes for filtration of micro and nanosize suspended particles. Membranes. 2013, vol. 3, pp. 375-388.

[3] PADMAVATHY, K.S., MADHU, G., HASEENA, P.V. A study on effects of pH, adsorbent dosage, time, initial concentration and adsorption isotherm study for the removal of hexavalent chromium $(\mathrm{Cr}(\mathrm{VI}))$ from wastewater by magnetite nanoparticles. Procedia Technology. 2016, vol. 24, pp. 585-594.

[4] HSU, C.C., WU, C.S., LIU, Y.L. Multiple stimuli-responsive poly(vinylidene fluoride) (PVDF) membrane exhibiting high efficiency of membrane clean in protein separation. Journal of Membrane Science. 2014, vol. 450, pp. 257264.

[5] ZHU, J., ZHOU, S., LI, M., XUE, A., ZHAO, Y., PENG, W., XING, W. PVDF mixed matrix ultrafiltration membrane incorporated with deformed rebar-like $\mathrm{Fe}_{3} \mathrm{O}_{4}$-palygorskite nanocomposites to enhance strength and antifouling properties. Journal of Membrane Science. 2020, vol. 612, pp. 118467.

[6] LAI, J., SUNDERLAND, B., XUE, J., YAN, S., ZHAO, W., FOLKARD, M., MICHAEL, B.D., WANG, Y., Study on hydrophilicity of polymer surfaces improved by plasma treatment. Applied Surface Science. 2006, vol. 252, pp. 3375-3379.

[7] HOMOLA, T., DZIK, P., VESELY, M., KELAR, J., CERNAK, M., WEITER, M. Fast and low-temperature $\left(70^{\circ} \mathrm{C}\right)$ mineralization of inkjet printed mesoporous $\mathrm{TiO}_{2}$ photoanodes using ambient air plasma. ACS Appl. Mater. Interfaces. 2016, vol. 8, pp. 33562-33571. 